\title{
Same-different judgments with words and nonwords: A word superiority/inferiority effect
}

\author{
DEREK BESNER and ANITA JACKSON \\ University of Reading, Reading, England RG6 $2 A L$
}

\begin{abstract}
Subjects made same-different judgments on the basis of visual criteria to pairs of letter strings that were either words or nonwords. "Same" RTs were faster for words than nonwords, while "different" RTs were faster for nonwords. These results rule out a race model of parallel self-terminating component processes.
\end{abstract}

One aspect of the word superiority effect (WSE) refers to the robust finding that in same-different RT tasks, "same" decisions are invariably found to be faster when words rather than nonwords are matched (Baron, 1975; Barron \& Pittenger, 1974; Egeth \& Blecker, 1971; Eichelman, 1970; Henderson, 1974). Several possible explanations of this result have been considered.

One possibility is that a name code rather than a visual comparison forms the basis of a classification. Real words have name codes that are highly practiced and, thus, presumably more accessible than nonword name codes. This possibility gains some empirical support from an experiment by Forster and Chambers (1973) which shows that words are named significantly faster than pronounceable nonwords.

Eichelman (1970) attempted to refute this possibility by showing that word matches are sensitive to manipulations that correspond to different nodes or levels of involvement with memory, as suggested by Posner and Mitchell (1967). The kernel of Posner's early technique is the assumption that differences in RT that result from manipulations of stimulus type allow us to infer the involvement of different stages underlying the recognition process. Thus, from the finding that "same" decisions to stimulus pairs such as "AA" are 70-100 msec faster than to pairs such as "Aa," Posner has argued that the former represent an early level of processing in which there is minimal contact with memory and the response is based solely on visual criteria. The latter stimuli require sufficient contact with memory so as to allow stimulus equivalence through identification. This identification may take the form of naming, which in turn forms the basis of a code that is subsequently used for matching the stimuli.

Eichelman found that "physical" matches such as BREAD/BREAD were faster than "name" matches

The experiment reported here was carried out by the second author as part of an undergraduate project directed by the first author. The paper is sponsored by Max Coltheart, who takes full editorial responsibility for its content. such as BREAD/bread. Eichelman reasoned that the naming explanation could be refuted, since the WSF was still evident when physical rather than name comparisons were employed. The difficulty with this explanation is that it assumes that name and physical matching times have distributions that do not overlap. If there is any overlap, it is possible to obtain namephysical RT differences but still produce a WSE on the basis of those trials where a name match finishes prior to a physical match.

A second possibility assumes that the transitional probabilities of certain letter groups is sufficiently high to allow the subject to capitalize on this fact by allowing information from one part of the display to invoke the help of a superordinate stage for later processing. It is of little consequence to the argument whether the letter groups are processed serially in a left-to-right fashion or whether a parallel model with cross-talk between channels operates. The net effect of orthographic regularity may simply allow for faster extraction of stimulus information and/or for setting up a representation for purposes of comparison. Henderson (1974), however, has neatly demonstrated that orthographic regularity is not a necessary condition that contributes to the WSE. When transitional probability is controlled for, but some of the letter strings remain meaningful whereas others do not (e.g., FBI-IBF), a healthy WSE is still evident. Attempts to dismiss this finding by recourse to the argument that a name code is responsible fails to explain the further finding (Henderson, in press) that a purely visual operation involving a case change (FBI to fbi) abolishes the WSE. Since both of these findings are replicable (Jonasson \& Besner, Note 1), it suggests that name coding and orthography do not constitute a sufficient explanation of the WSE.

A third possibility is that the WSE is mediated by a comparison of word meaning. The semantic representation of a word might be accessed by a content addressable algorithm which makes use of such visual characteristics as word shape. This might explain why "fbi" in contrast to "FBI" does not produce a WSE. The lowercase version is rarely if ever seen; 
consequently, it may not address a memory location and be treated instead as a nonword.

The simplest way of testing the semantic comparison hypothesis is to stage a situation where equivalence of meaning is not a sufficient basis for a correct response. If we suppose that semantic and visual matches occur in parallel and that their distribution of finishing times overlap, then it follows that, by the appropriate manipulation, rendering the prior completion of a semantic match irrelevant would result in the disappearance of the WSE.

\section{METHOD}

\section{Stimuli}

The stimuli were all strings of five letters comprised of three consonants and two vowels. The nonwords were constructed by rearranging the $\mathrm{CV}$ structure of the real words into either CCCVV or VVCCC combinations which were all orthographically illegal. For example, AECDN and BRDAE are the nonword counterparts of DANCE and BREAD. An attempt was made to exclude those letters whose upper- and lowercase versions were highly similar and those letters, such as " $L$," whose upper- and lowercase versions contain a considerable difference in width. The words were 10 words sampled from the set of stimuli used by Barron and Pittenger (1974).

There was a total of 240 trials, of which 120 required a "same" decision and 120 a "different" decision. The six conditions were as follows: (1) identical words of the same case appearing in both upper- and lowercase, e.g., BREAD/ BREAD and bread/bread; (2) identical nonwords, e.g., BRDAE/ BRDAE and brdae/brdae (Conditions 1 and 2 contained 60 trials each); (3) identical words in different case, e.g., BREAD/ bread, bread/BREAD; (4) as in 3, but with nonwords; (5) word pairs that were different in meaning and either same or different in case; (6) different nonword pairs in either same or different case. Conditions 3-6 each contained 30 trials; all of these conditions required a "different" response, while Conditions 1 and 2 required a "same" response.

The stimuli were displayed one above the other in the center of a CRT slaved to a PDP-12 computer. A small panel in front of the subject contained a set of response keys to which subjects responded "same" with their preferred hand and "different" with their nonpreferred hand. There were a number of CRTs arranged so that a maximum of five subjects could be run concurrently. The display terminated when the last subject made a response; $600 \mathrm{msec}$ after termination of the display a new trial began.

The 20 undergraduate students were instructed that the criterion for responding "same" was physical identity. In other words, the letter strings had to have the same physical appearance (i.e., the same case) in order to justify a "same"

Table 1

Mean RT (in Milliseconds) and Error Rates According to Condition

\begin{tabular}{|c|c|c|c|c|c|c|}
\hline & \multicolumn{2}{|c|}{$\begin{array}{l}\text { "Same" } \\
\text { Response }\end{array}$} & \multicolumn{4}{|c|}{ "Different" Responses } \\
\hline & $\begin{array}{l}\text { BREAD } \\
\text { BREAD }\end{array}$ & $\begin{array}{l}\text { BRDAE } \\
\text { BRDAE }\end{array}$ & $\begin{array}{c}\text { BREAD } \\
\text { bread }\end{array}$ & $\begin{array}{c}\text { BRDAE } \\
\text { brdae }\end{array}$ & $\begin{array}{c}\text { BREAD } \\
\text { grape }\end{array}$ & $\begin{array}{c}\text { BRDAE } \\
\text { prgae }\end{array}$ \\
\hline RT & 574 & 636 & 658 & 637 & 642 & 613 \\
\hline $\begin{array}{l}\text { Percent } \\
\text { Error }\end{array}$ & 2.25 & 6.75 & 8.0 & 2.8 & 3.5 & 4.2 \\
\hline
\end{tabular}

response. Anything other than visual identity required a "different" response. The subjects were informed of the number of practice trials (30), the number of test trials (240), the response probabilities $(50 / 50)$, and the approximate duration of the experiment $(15 \mathrm{~min})$. They were further encouraged to respond as quickly as possible, but at the same time to attempt to keep their error rate below $10 \%$.

\section{RESULTS AND DISCUSSION}

The practice trials and those trials on which errors were committed were excluded from the analysis. Mean RTs and error rates associated with each condition can be seen in Table 1 .

Clearly, the superiority of words over nonwords for "same" decisions is a marked one $(t=6.96, \mathrm{df}=19$, $\mathrm{p}<.01)$. This result is sufficient to rule out a model where the WSE results from a race between an abstract (possibly semantic) match and a match which is dependent upon purely low-level visual analysis. The model can be ruled out because the statistical redundancy inherent in a race of self-terminating component processes with overlapping distributions has been eliminated by the task constraints. Those "semantic" matches which finish prior to the completion of visual analysis may not be used as a basis for classification because they do not contain the necessary visual information. That is, a semantic match would indicate that both BREAD/BREAD and bread/BREAD are identical sets of stimuli, yet the task is one such that the latter pair require the classification "different" because their visual forms differ.

There is, however, a way in which meaningfulness may affect response time without being involved in the extraction or comparison process. Baron (1975) has argued that meaningfulness need not affect capacity to do the task or sensitivity to the relevant information, but may affect response bias toward "same" possibly because of some basic compatibility of meaning with the "same" response. This is not an implausible argument, though perhaps the notion of compatibility is inherently weak given its operational definition. It seems possible to argue instead that early finishing semantic comparisons, though irrelevant, may serve to alter decision criteria on visual analysis still in progress.

A further weakness of the compatibility argument is its implied prediction of a word inferiority effect for "different" classifications. This creates problems because, although Baron (1975). found a word inferiority effect for "different" classifications, Henderson (1974) found the opposite and others (Barron \& Pittenger, 1974; Egeth \& Blecker, 1971) found no difference.

While the pattern of results from the "different" response of the present experiment are consistent with Baron's compatibility argument, there are clearly other factors in play. An analysis of variance performed 
on the "different" responses reveals that the main effect of WORDS vs. NONWORDS is significant $(F=9.86$, $\mathrm{df}=1 / 19, \mathrm{p}<.01)$, as well as the main effect of different letters vs. same letters (Conditions 3 and 4 vs. 5 and 6) $(\mathrm{F}=11.30, \mathrm{df}=1 / 19, \mathrm{p}<.01)$. The interaction was not significant. Clearly, above and beyond being a word, sharing the same name-though not the same visual features-is deleterious to responding "different" even on the instructed basis of visual criteria.

In conclusion, it might be argued that there is as yet little direct evidence that the same-different RT versions of the WSE involve processes that operate at any stage other than a response selection and execution one.

\section{REFERENCE NOTE}

1. Jonnason, J. T., \& Besner, D. Unpublished experiments.

\section{REFERENCES}

BARON, J.Successive stages in word recognition. In P. M. A. Rabbitt \& S. Dornic (Eds.), Attention and performance V. London: Academic Press, 1975.
Barron, R. W., \& Pitrenger, J. B. The effect of orthographic structure and lexical meaning on "same-different" judgments. Quarterly Journal of Experimental Psychology, 1974, 26, 566-581.

Egeth, H., \& Blecker, D. Differential effects of familiarity on judgments of sameness and difference. Perception \& Psychophysics, 1971, 9, 321-326.

Eichelman, W. Familiarity effects in a simultaneous matching task. Journal of Experimental Psychology, 1970, 86, 275-282.

Forster, K., \& Chambers, S. Lexical access and naming time. Journal of Verbal Learning and Verbal Behavior, 1973, 12, 627-635.

HENDERSON, L. A word superiority effect without orthographic assistance. Quarterly Journal of Experimental Psychology, 1974, 26, 301-311.

Henderson, L. Word recognition. In N. S. Sutherland (Ed.), Tutorial essays in experimental psychology. Potomac, Md: Erlbaum, in press.

Posner, M. I., \& Mitchell, R. Chronometric analysis of classification. Psychological Review, 1967, 74, 392-409.

(Received for publication August 22, 1975.) 